\title{
The Great Coastal Gale of 2007 from Coastal Storms Program Buoy 46089
}

\author{
Richard L. Crout, Ian T. Sears, and Lea K. Locke \\ NOAA National Data Buoy Center \\ 1007 Balch Blvd. \\ Stennis Space Center, MS 39529 USA
}

\begin{abstract}
During the first three days of December 2007, a series of powerful coastal storms and an associated wave approached the coasts of Washington, Oregon, and British Columbia in rapid succession. The winter storms pummeled the states with a maximum 220 kilometers per hour gust along the coast and generated the first-ever hurricane warning in the Pacific Northwest by the National Weather Service.
\end{abstract}

The Coastal Storms Program of the National Oceanic and Atmospheric Administration had the National Data Buoy Center deploy a three meter discuss buoy 150 kilometers west of Tillamook, OR to monitor just this type of storm. The buoy was moored in $\mathbf{2 2 0 0}$ meters of water in 2005 . Although two other buoys closer to the coast were torn from their moorings, the CSP Tillamook buoy remained on station and reported wind speed and direction, barometric pressure, air temperature, waves, and currents throughout the storms. Water temperature and a redundant wind sensor failed during 3 December. The redundant wind sensor failed as the winds approached $23 \mathrm{~m} / \mathrm{s}$. The buoy survived storm generated significant wave heights that exceeded 14 meters and remained on station and reporting until the buoy was recovered in February 2008 . Upon recovery, it was discovered that the wind fin that orients the buoy into the wind was bent against the buoy structure, resulting in stress fractures in the metal at several locations.

Waves and currents continued to be measured and transmitted during and after the storm. The data are presented in an effort to determine the impact of waves and buoy motion on current profile data.

\section{INTRODUCTION}

The Coastal Storms Program (CSP) is a cross-cutting National Oceanic and Atmospheric Administration (NOAA) effort to improve the resiliency of coastal communities to coastal storms. In the past, CSP has funded buoys, tide stations, modeling efforts, bathymetric surveys, outreach material, and wind profilers to help understand the impact of coastal storms on coastal communities. The first pilot project was in northeast Florida and was centered on the St. John River. The Pacific Northwest pilot followed the Florida pilot and subsequent pilots include Southern California and the northern Gulf of Mexico.

Among the efforts proposed for the CSP Pacific Northwest pilot was a buoy offshore of the Washington and Oregon coasts. National Data Buoy Center (NDBC) had already placed buoys along these coasts off Port Orford, OR, on Stonewall Banks, OR, at the Columbia River Bar, WA, and off Cape Elizabeth, WA. These buoys are between 30 and 50 kilometers offshore. The Tillamook buoy (46089) was placed 150 kilometers offshore in order to provide accurate data farther offshore so that a longer-term, quality forecast could be provided to coastal residents.

\section{ANATOMY OF THE GREAT COASTAL GALE}

The Great Coastal Gale of 2007 began as a strong low that formed from the remnants of two typhoons in the central Pacific and was carried toward the Pacific Northwest. A series of Storm Summary Messages issued by the Hydrometeorological Prediction Center in Camp Springs, MD contained phrases such as: "series of major early winter storms", "bringing very strong winds to coastal sections of Washington, Oregon and northwest California", "hurricane force warnings for areas just offshore", and "major early winter storm continuing to pound the Pacific northwest". It was the first occurrence of the Hurricane force warning in the Pacific Northwest (Storm Summaries, 2007). 
The series of storms arrived in four waves (fig. 1). The first developed off the coast of Washington Saturday 1 December and brought high winds and cold temperatures. The second wave arrived late on Sunday 2 December and reached its peak intensity just before striking the northern coast of Washington. A wave associated with the last low pressure system arrived early Monday and helped to maintain the strong pressure gradient before the arrival of the strongest system later in the day Monday 3 December.

The duration of the combined storms rank the Great Coastal Gale of 2007 as one of the strongest storms to hit the Pacific Northwest. Other storms in the area, such as the Columbus Day Storm of 1962, were stronger, but were shorter in duration.

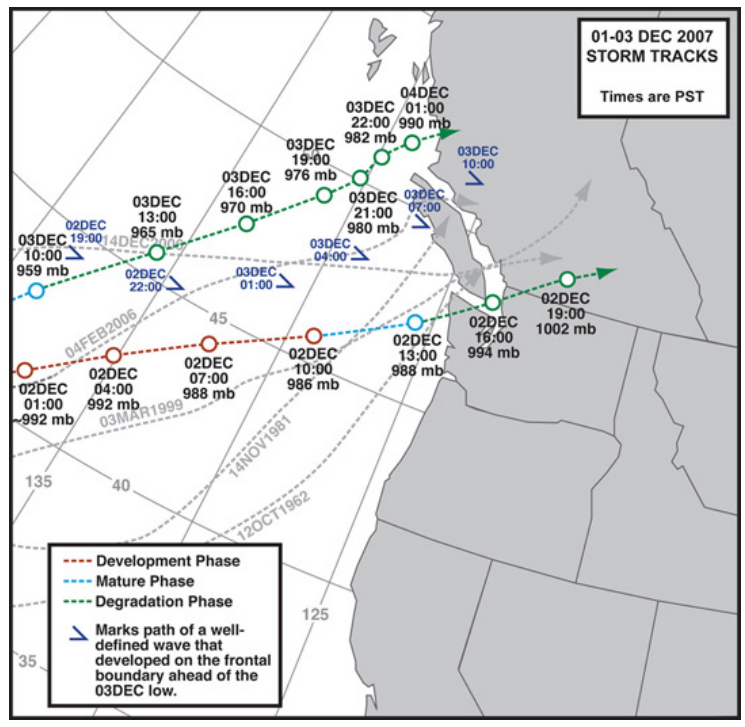

Fig. 1 The storm tracks of lows and waves that were part of the Great Coastal Gale of 2007 (Read, 2007).

Wind speed gusts on the coast reached $61.8 \mathrm{~m} / \mathrm{s}$ at Holy Cross, WA and $53.7 \mathrm{~m} / \mathrm{s}$ at Bay City, OR. The highest speed recorded for the event was inshore at Naselle Ridge, WA where the speed reached 65.9 $\mathrm{m} / \mathrm{s}$. Maximum wind speeds recorded at NDBC buoys were gusts of 34.3 at the Stonewall Banks buoy, $30.2 \mathrm{~m} / \mathrm{s}$ at the Columbia River Bar buoy, and $30.4 \mathrm{~m} / \mathrm{s}$ at the Tillamook buoy. Sustained winds exceeded $10 \mathrm{~m} / \mathrm{s}$ at each of the buoys.

\section{THE GREAT COASTAL GALE AT NDBC BUOY 46089}

The Tillamook buoy, sponsored by the Coastal Storms Program, weathered the Great Coastal Gale of 2007 and provided data during and after the storm. The fall in barometric pressure and rise in wind speeds is presented in Fig. 2. The first feature centered at $00 \mathrm{Z} 2 \mathrm{Dec}$ is a deepening low that is accompanied by winds rising to between 13-14 m/s. Following this feature is a series of lows and waves as shown in fig. 2 . Each pressure drop is associated with an abrupt increase in the wind speed. Wind speeds exceeded $10 \mathrm{~m} / \mathrm{s}$ for a period of almost 48 hours as these features passed the buoy. A peak sustained wind speed of 22.8 $\mathrm{m} / \mathrm{s}$ at $0800 \mathrm{UTC}$ and a maximum gust of $30.4 \mathrm{~m} / \mathrm{s}$ were transmitted at $0900 \mathrm{UTC} 3$ December. 

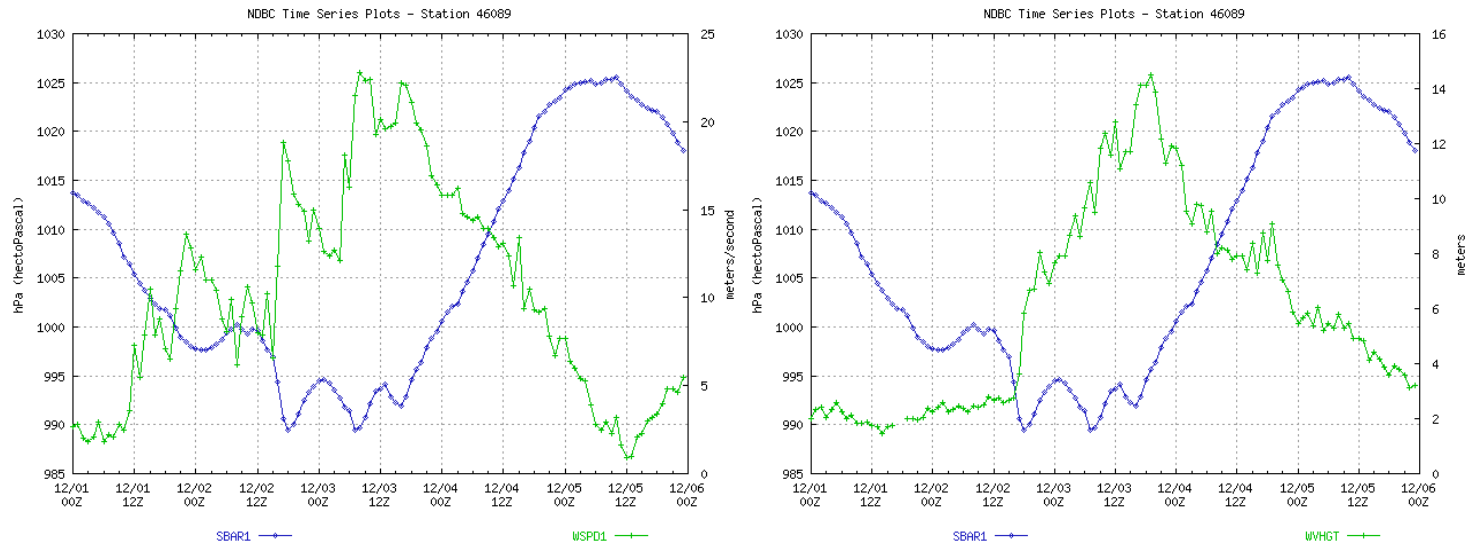

Fig. 2. Left: Barometric pressure and wind speed. Right: Barometric pressure and wave height at Buoy 46089.

The wave heights (fig. 3) do not appear to be impacted by the winds associated with the deepening low during the first 36 hours of the period presented, even though winds exceed $10 \mathrm{~m} / \mathrm{s}$ during portions of the period (fig. 2). The wave height builds quickly as the second and third low pressure areas pass, eventually resulting in wave heights exceeding 14 meters on 3 December (fig. 3). Winds associated with the deepening low are from the west-southwest. The rapid increase in wave heights coincides with the shift to a southerly wind direction as the second low pressure area approaches, which oppose the prevailing southward flowing currents associated with the California Current.
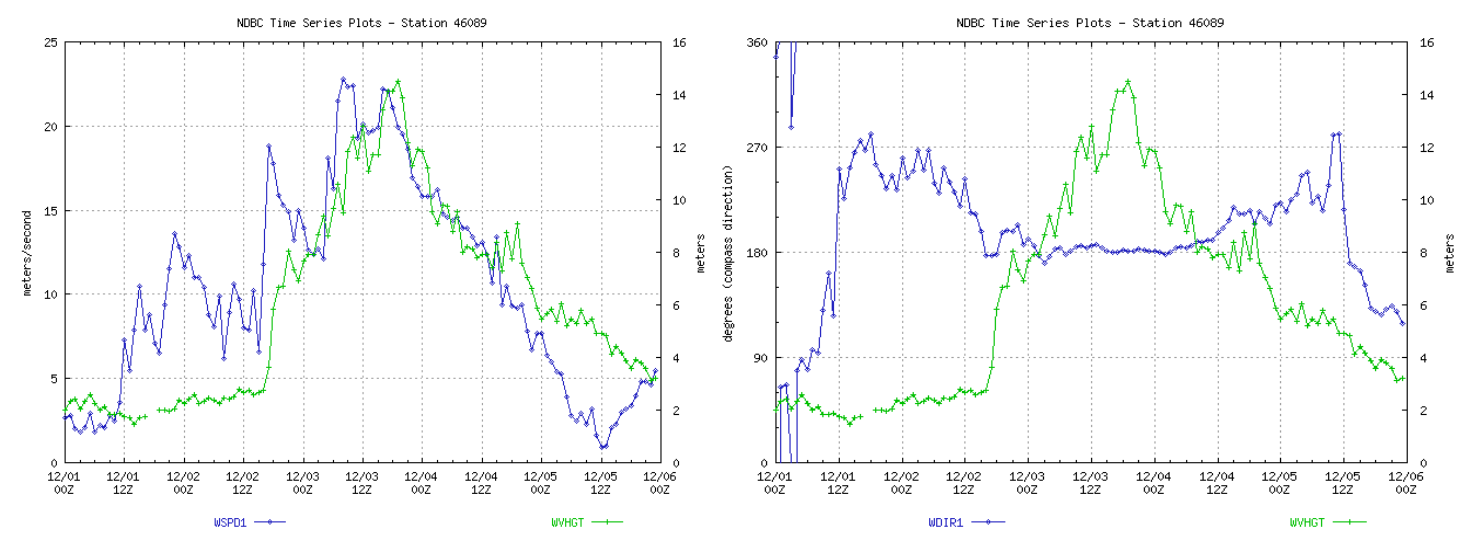

Fig. 3. Left: Wave height and wind speed. Right:Wave height and wind direction from Buoy 46089.

Significant wave heights at the more nearshore buoy, 46029, are slightly higher than those transmitted from Buoy 46089, until 12Z 3 December 2007 (fig. 4). The decreasing waves appear to occur after Buoy 46029 was torn from its mooring and went adrift at 0730Z 3 December 2007. At about this time, the wave lengths at 46029 were approximately 315 meters (calculated from the dispersion relationship), while the depth of the water column at its mooring location is 135 meters. The waves derived from the buoy interact with the bottom and would be reacting as shallow water waves at this point. This phenomenon could be responsible for the drop in wave heights at the buoy, while waves continue to build farther offshore at Buoy 46089. A record of the buoy tilt shows that during this period the tilt of the buoy reached $45^{\circ}$ several times before finally recording a tilt of $88^{\circ}$ at the height of the storm. 


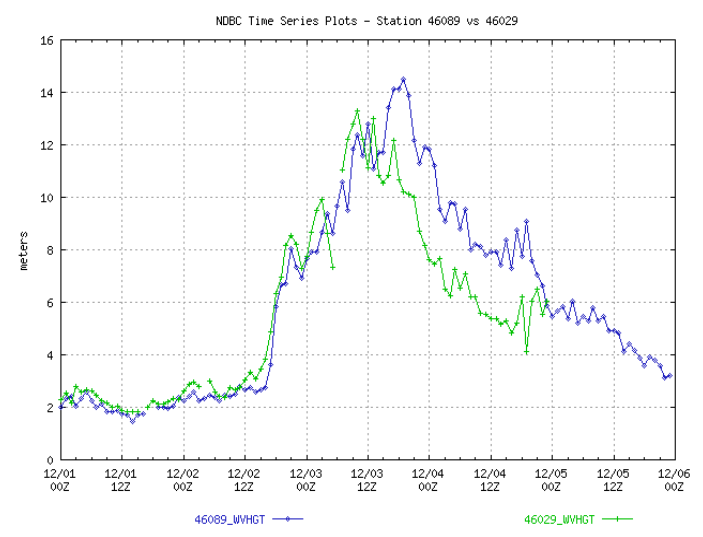

Fig. 4. Significant wave heights from Buoys 46029 and 46089.

\section{IMPACT TO BUOY 46089}

The mast on buoy 46089 sustained considerable damage from the elements during the storm. Pictures taken during recovery, two and one-half months after the storm, show the wind vane on the aft side of the buoy bent around the mast. It is not possible to tell whether the damage is from waves, the wind, or a collision with a vessel. Closer inspection shows stress fractures at several places on the mast. The damage was significant enough that the buoy had to be returned to NDBC and another shipped to take its place.

\section{IMPACT OF BUOY MOTION ON CURRENT PROFILE}

One of the data quality issues of interest to NDBC is the impact of the environment on the collection of currents from the buoy. NDBC currently has two methods of using an Acoustic Doppler Current Profiler (ADCP) to collect data. In the first method, a cage below the bridle holds the downward-looking ADCP. The cage is attached to the bridle/buoy by a chain that should remove some of the buoy motion from the ADCP. The second method is to seat the ADCP into the buoy bridle. One of the implications of the second method is the need to sample quickly $(0.5$ to $1 \mathrm{~Hz})$ and for an extended period of time, nominally, three to five minutes, in order to average the buoy motion out of the ADCP measurement. The ADCP at 46089 was located in a cage below the buoy during this event.

The typical tidally influenced southward flow along this section of the coast of the Pacific Northwest is shown in the left side of fig. 5. The ADCP data is collected hourly in 16 meter bins. The first bin is centered at 24 meters depth and the last bin is at 328 meters depth. The right side of figure 5 shows flow directed towards the south for the first 36 hours of the plot and then the currents become disorganized and flow patterns are more difficult to interpret. Two conditions may contribute to the disorganization represented here. The horizontal motion of the buoy due to the winds pushing the buoy in a direction could impact the currents measured by the ADCP, if the buoy is translating quickly in one direction. The second condition is movement of the buoy in all three axes in response to large waves. 


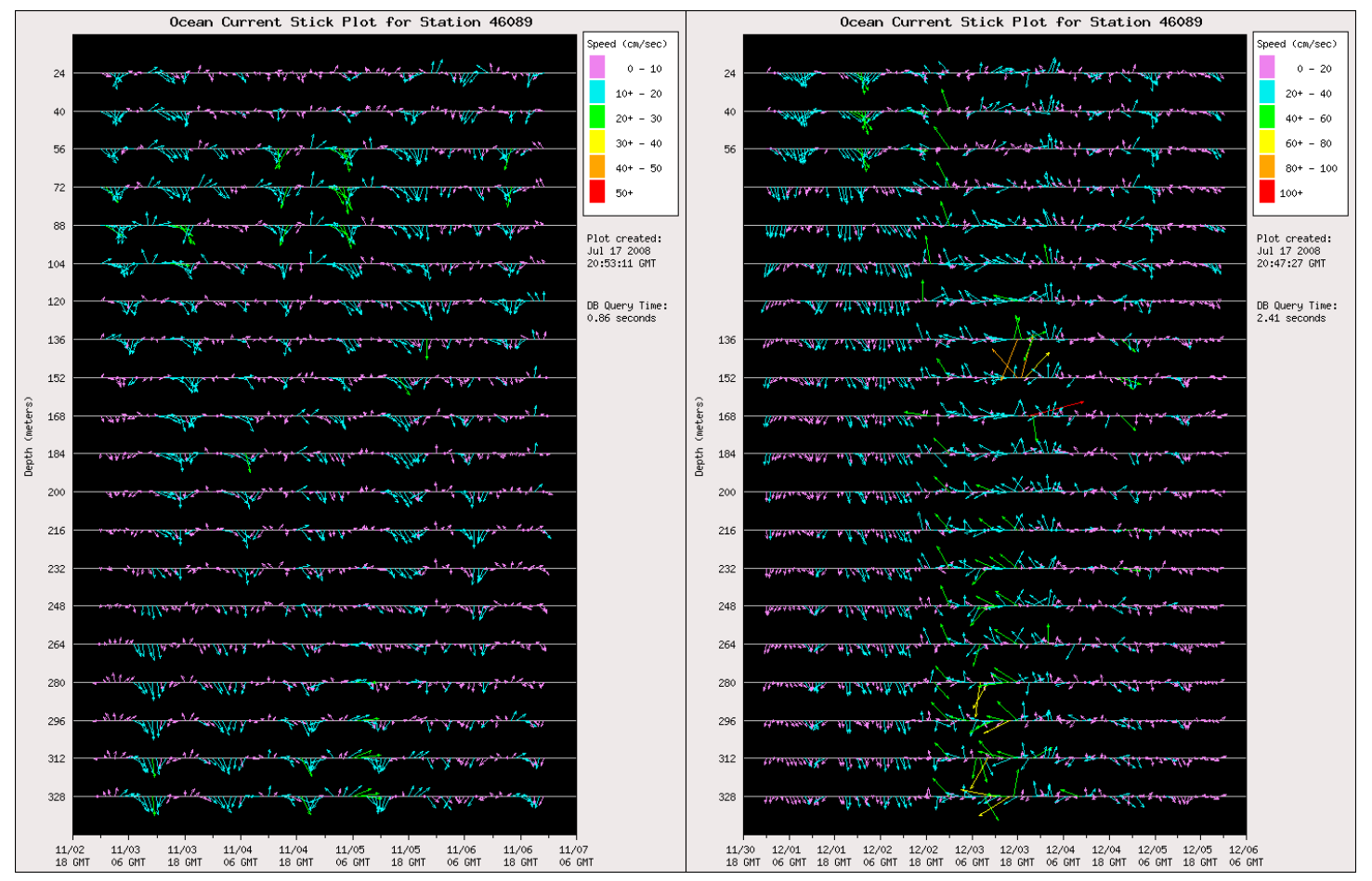

Fig. 5. Left: Five-day stick plots of current velocities at Buoy 46089 during Nov 2007. Right: Fiveday stick plots of current velocities at Buoy 46089 during Dec 2007 . North is toward the top of the figure and the scales are given for each plot. Time advances from left to right.

An analysis of the drift of the buoy was possible using position data gathered from the buoy. Vectors indicating the magnitude and direction of drift each hour during the first three days of December 2007 were calculated and are presented in fig. 6 . The drift exhibits a strong diurnal component that is modified by strong winds, but the contribution to the current speeds in the upper water column $(\sim 5 \mathrm{~cm} / \mathrm{s})$ do appear to be large during the first day. Higher buoy translation speeds during the latter half of the period do not appear to impact the near surface currents measured by the ADCP.

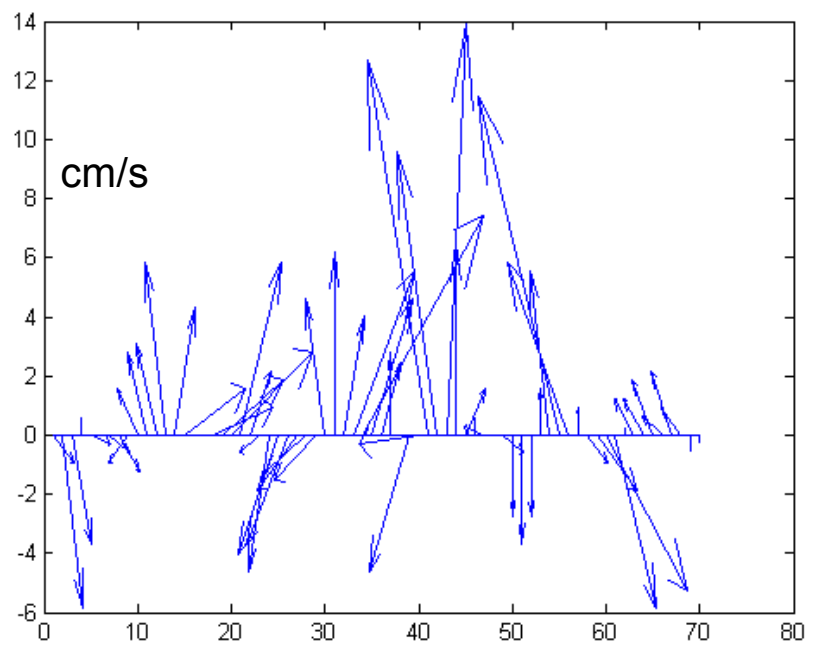

Sequential hours of event starting 1 December

Fig. 6. Hourly movement vectors for Buoy 46089 from position information. 
A comparison of the significant wave height and the cross-shelf and along-shelf components of the current at 24 meters depth are presented in fig. 7. The current components before the onset of high waves are slightly onshore and to the south. A semi-diurnal tidal component is evident in the plot of currents. Once the waves reach between 3 and 4 meter heights, the currents begin to exhibit higher frequency oscillations, which continue until the waves calm to around 6 meters, when the semi-diurnal component of the tide becomes evident again. Because of the rapid rise in the significant wave height (4 meters in 3 hours), it is difficult to determine the significant wave height where the current data are corrupted. Fig. 7 also shows the cross-shelf and along-shelf currents from a depth of 328 meters. The deeper currents exhibit similar behavior to the near-surface currents.
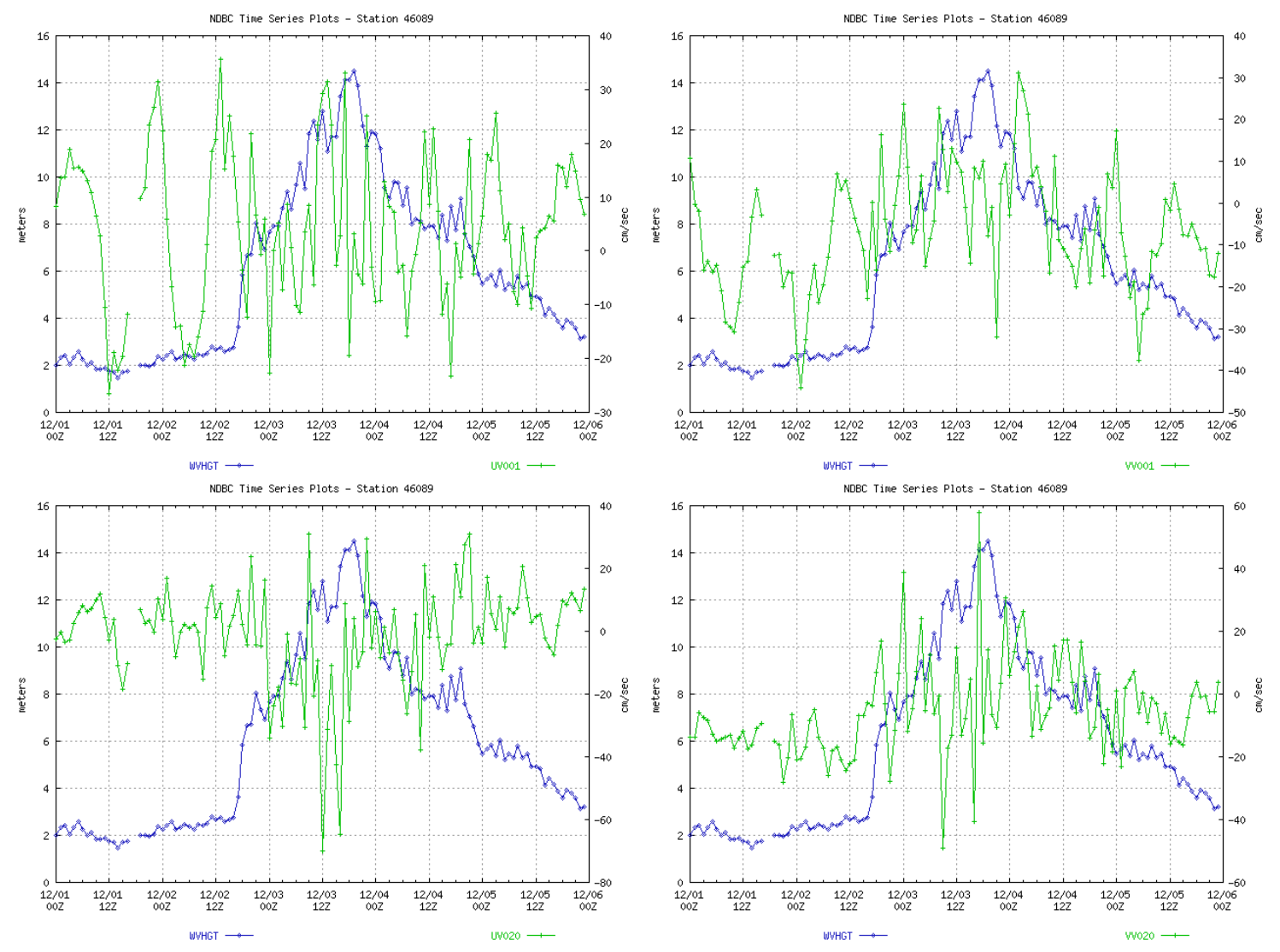

Fig. 7. Top Left: Surface cross-shelf (UV001). Top Right: Surface along-shelf (VV001). Bottom Left: Deep cross-shelf (UV020). Bottom Right: Deep along-shelf (VV020) components of the current and the significant wave heights. The cross-shelf current component is positive toward the coast. The along-shelf current component is positive toward the north.

Error velocity is a measure of the homogeneity of the flow measured by an ADCP. High error velocity values indicate that the flow is not homogeneous and therefore measurements made with the ADCP are unreliable. For NDBC buoys with ADCPs, levels of error velocity less than $10 \mathrm{~cm} / \mathrm{s}$ are considered very good. Values in excess of $20 \mathrm{~cm} / \mathrm{s}$ indicate very questionable data. Fig. 8 indicates that the error velocities near the surface (24 meters) and at depth (368 meters) are large and the resulting cross-shelf and alongshelf components of the velocity should not be trusted. Error velocities following the wave height decrease indicate that speeds are reliable again.

The ADCP at Buoy 46089 during this deployment was in a cage with the transducers at approximately 4 meters below the surface. While the cage minimizes the rocking motion of the buoy in response to waves, it is impacted as the buoy rides over wave crests and through wave troughs. The dynamics of the cage motion are not well understood under these conditions, but it is obvious that the measurements from the ADCP are not reliable. 


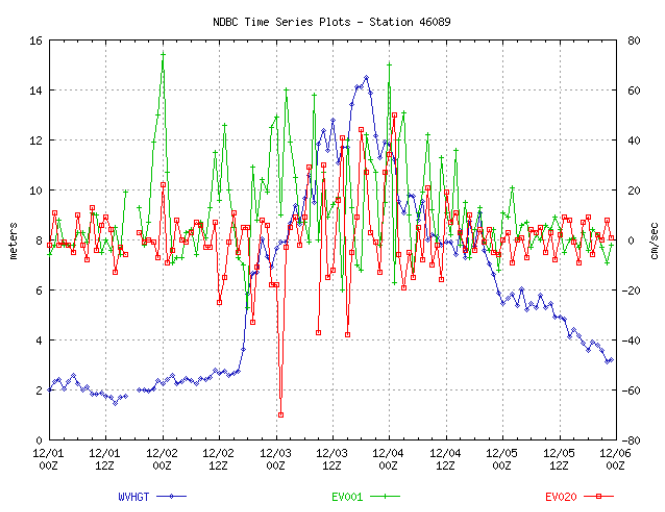

Fig. 8. The error velocity at 24 (green) and 368 (red) meters and the wave heights from Buoy 46089 for 1-5 December 2007.

\section{CONCLUSIONS}

An NDBC buoy (46089) sponsored by the Coastal Storms Program survived one of the strongest recorded storms to hit the Pacific Northwest. The buoy provided real-time meteorological, wave, and ocean current data before, during, and after the storm, although it was damaged. The CSP buoy provided information that aided the National Weather Service Forecast Offices in mitigating the damage to life and property on the Washington and Oregon coasts during the Great Coastal Gale of 2007.

Additionally, the gale provided information important in an NDBC assessment of the quality of ADCP data collected from the buoy. The current profile data appears to provide questionable data as the wave heights quickly increase from 3 to 6 meters. Although it is not possible to determine the wave height where the ADCP data are impacted, it was possible to determine that the primary cause of the decrease in data quality were the waves. Even though there were other contributing factors (such as the translation of the buoy due to wind and current), it appears that there is a wave height threshold in which the buoy is able to still report reliable data. This threshold was clearly surpassed during the December event, but because wave heights rose by such a considerable amount in such a short amount of time, it is impossible to give the threshold limit a definitive value.

A related effort to compare bottom-mounted, upward looking ADCP data to buoy-mounted, downward-looking ADCP data is currently underway. The combination of results from these two efforts will increase the quality of current profile data from NDBC ADCPs.

\section{REFERENCES}

Read, Wolf, “The Great Coastal Gale of Dec 1-3, 2007”, Journal Notes, 2007

Storm Summary Number 1, NWS Hydrometeorological Prediction Center, Camp Springs, MD, 2 Dec 2007

Storm Summary Number 2, NWS Hydrometeorologcial Prediction Center, Camp Springs, MD, 3 Dec 2007

Storm Summary Number 3, NWS Hydrometeorological Prediction Center, Camp Springs, MD, 3 Dec 2007

\section{ACKNOWLEDGMENTS}

Ted Mettlach of Science Applications International Corporation provided informative discussions regarding waves from the NDBC buoys and their potential impact on measurement of ocean currents. 